\title{
The effects of duration of territorial residence on aggression in convict cichlids
}

\author{
MICHAEL H. FIGLER, HOWARD L. CANOUNE, and MELISSA H. KITNER-TRIOLO \\ Towson State University, Towson, Maryland
}

Resident convict cichlid aggression against a conspecific intruder was measured after 24 or $48 \mathrm{~h}$ of sole territorial residence. Latency of attack was significantly shorter and the intensity of attack was significantly higher in the 48-h residence condition than in the 24 -h condition. These temporal changes in aggression fit the time frame for the development of the territorial prior residence effect in this species, apparently reflecting an underlying proximate mechanism in its occurrence.

A series of recent studies using convict cichlids, Cichlasoma nigrofasciatum Günther (Figler \& Einhorn, 1983; Figler \& Evensen, 1979; Figler \& Peeke, 1978; Figler, Wazlavek, Spencer, \& Gussio, 1985), and jewel fish, Hemichromis bimaculatus Gill (Figler, Dyer, Streckfus, \& Nardini, 1975; Figler, Klein, \& Peeke, 1976), have investigated the prior residence effect in fish. This phenomenon refers to the fact that in a territorial encounter, the territory owner is typically successful in repelling a conspecific intruder (Braddock, 1949).

Various factors have been shown to influence the resident's dominance advantage. These factors include relative size of resident and intruder (Figler, Wazlavek, Walko, \& Chaves, 1985), length of territorial residence (Figler \& Einhorn, 1983; Figler et al., 1976), intra- and extraterritorial cues (Figler et al., 1975; Figler \& Einhorn, 1983; Figler, Wazlavek, Spencer, \& Gussio, 1985), and past experience (Figler, et al., 1976). The proximate mechanisms underlying the prior residence effect, however, remain unclear.

A number of hypotheses have been developed, but have not been supported (see Figler \& Einhorn, 1983). Recently, however, Figler and Einhorn (1983) have suggested that a resident's initial fear in the territory (neophobia) habituates during a $24-48 \mathrm{~h}$ period, making the resident more aggressive (less inhibited by fear) than the intruder. This heightened aggression is suggested by the consistent finding in the above-mentioned studies that the resident reliably attacks first in an encounter, and that initiating attack is a reliable predictor of ultimate dominance. The notion of a 24-48 $\mathrm{h}$ habituation period derives from the fact that in $C$. nigrofasciatum the prior residence effect occurs somewhere between a 24-48 $\mathrm{h}$ period of residence in a geographical area.

If this habituation-of-fear/increase-in-aggression hypothesis is tenable, then residents should show an increase in aggression across the time period concomitant with the development of the territorial dominance advan-

Reprint requests should be sent to Michael H. Figler, Department of Psychology, Towson State University, Towson, MD 21204. tage. Therefore, the present preliminary study compared levels of aggression in residents that had occupied their territories for either 24 or $48 \mathrm{~h}$ prior to a territorial intrusion by a conspecific.

\section{METHOD}

\section{Subjects}

Subjects were 19 male and female convict cichlids (Cichlasoma nigrofasciatum Günther) maintained for several days in two 65 liter (78 $\times 32 \times 31 \mathrm{~cm})$ aquariums under constant aeration, filtration, and stable water temperature $\left(26^{\circ} \mathrm{C}\right.$ ), and fed a diet of brine shrimp (Artemia salina) once per day. The room in which the fish were kept was maintained on a $14 \mathrm{~h}$ day $/ 10 \mathrm{~h}$ night cycle at the same temperature. Sixteen fish, approximately $3 \mathrm{~cm}$ in length from the tip of the snout to the base of the caudal fin, were selected to serve as residents, and were netted and placed in individual aquariums (described below). These aquariums were numbered and then randomly assigned to either the $24-$ or $48-\mathrm{h}$ residence condition. The remaining 3 fish, approximately $1.5 \mathrm{~cm}$ in length, were randomly used as intruders in the present study.

\begin{abstract}
Apparatus
The apparatus used in the present experiment was basically the same as that used by Figler and Evensen (1979), Figler and Einhorn (1983), and Figler, Wazlavek, Spencer, and Gussio (1985). All resident fish were placed in nonaerated and nonfiltered individual aquariums (21 liters, $41 \times 21 \times 26 \mathrm{~cm}$ ) containing a coarse gray gravel substrate, like that used by Figler and Einhorn (1983). One of two territorial markers-a terra-cotta pot ( $7.5 \mathrm{~cm}$ diameter) laid on its side, or a 9-cm-high clump of plastic plants-was placed against the far side of each tank. The individual aquariums were arranged in pairs, with the short side of the tanks facing each other, and each tank pair was separated from other tank pairs by a cardboard partition. A glass stimulus tube $(45 \mathrm{~cm}$ high, $5.7 \mathrm{~cm}$ diameter) was used to present the intruder. A Model 292-8 Rustrak eight-channel event recorder was used to record the dependent measures, described below.
\end{abstract}

\section{Procedure}

One half of the residents $(n=8)$ were tested for aggression toward an intruder after a $24-\mathrm{h}$ residence period, and the remaining residents $(n=8)$ were tested for aggression after a 48 -h residence period. Residents in both conditions were tested for a period of $20 \mathrm{~min}$.

At the beginning of a testing session, an opaque white Plexiglas partition was inserted, dividing the resident's tank into two equal compartments, with the resident on the side of the tank with the territorial marker. The stimulus tube, filled to the same level as the tank and containing the intruder, was placed in the other side of the resident's tank. After a 15-min adaptation period, the Plexiglas divider was removed and the 20-min testing session began. Two dependent measures were recorded: 


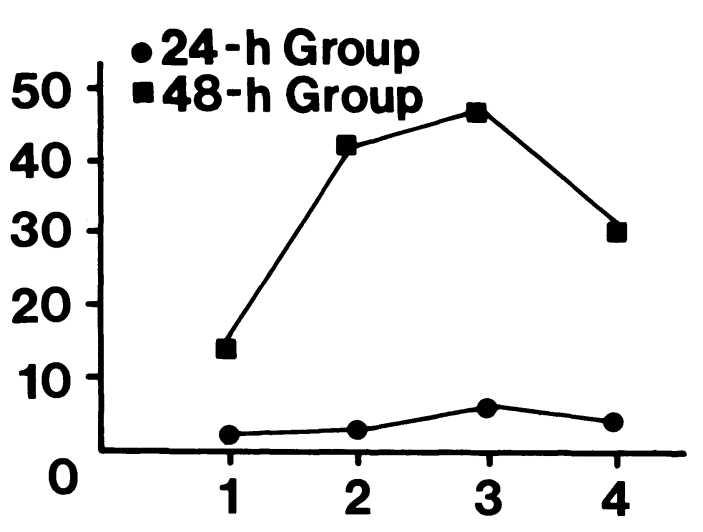

OBSERVATION PERIODS

Figure 1. Mean biting frequency per 5-min observation period as related to duration of territorial residence.

(1) latency to first bite of the resident, and (2) the number of bites delivered to the stimulus tube by the resident. A bite was defined as any open- or closed-mouthed butting of the stimulus tube, usually associated with a charge or a lunge.

\section{RESULTS}

The 20-min test data were divided into four 5-min observation periods for analysis. Figure 1 shows that the biting frequency for both treatment groups increased across the first three 5-min observation periods and then declined. In each observation period, however, the 48-h group bit more frequently than the 24-h group.

A two-factor mixed-model (2 durations of residence $x$ 4 observation periods) analysis of variance of biting frequency revealed a significant duration of residence effect $[F(1,14)=7.34, p<.05]$. There was also a significant observation period effect $[F(3,42)=3.90, p<.05]$. However, the duration of residence $\times$ observation period interaction was not significant $[F(3,42)=2.59, p>.05]$.

A Mann-Whitney $U$ test (two-tailed) was used to compare the latency to first bite for the 24-h (mean = $859.25 \mathrm{sec}, S D=504.32$ ) and 48 -h (mean $=227.13 \mathrm{sec}$, $S D=166.83$ ) groups. The results showed a significantly longer latency to first bite for the 24-h group than for the 48 -h group, $U=11, p<.05$. Also of interest is the fact that only 3 of the subjects in the 24-h group showed any biting at all during the test session, but all 48-h group subjects showed some biting. A Fisher exact probability test (two-tailed, $p<.05$ ), showed that the $48 \mathrm{~h}$ group had a significantly higher proportion of responders than did the 24-h group.

\section{DISCUSSION}

The present results clearly show that the level of aggression significantly increases between $24 \mathrm{~h}$ and $48 \mathrm{~h}$ of residence, the same time frame for the development of a stable prior residence effect in this species (Figler
\& Einhorn, 1983). Also, the latency to first bite was significantly longer in the 24-h group than in the 48-h group, most likely reflecting a higher level of fear in the former group.

Fear behavior-exhibited by blanching of body color, freezing behavior, hiding behind the plant or in the pot, and "jerk swimming", (see Figler \& Einhorn, 1983) - was very prominent in the 24-h subjects. In 5 of those subjects, this fear behavior apparently completely inhibited the elicitation of aggression. Although fear behaviors in the present study were not quantitatively measured, it would be expected that there would be a significant decrease across the 24- to 48-h period, concomitant with the increase in aggression.

As suggested by Figler and Einhorn (1983), after a resident has been in its territory for approximately $24-48 \mathrm{~h}$, it is more aggressive (less fearful) than the intruder. This higher level of aggression by the resident results in the resident's attacking first and eventually dominating the intruder. Bronstein (1985) and Evans (1985) have reported that in Siamese fighting fish (Betta splendens), the pair member that has a higher level of aggression prior to an encounter is significantly more aggressive than its adversary throughout the encounter. Their findings suggest that the initiation of attack by a territorial resident might be interpreted as an asymmetry in fighting ability (Maynard Smith \& Parker, 1976) by an intruder. In other words, the uncorrelated asymmetric advantage originating by a resident's being in an area first may be translated into an asymmetric advantage in fighting ability through the previously described habituation of fear/increase in aggression process.

\section{REFERENCES}

BraddoCK, J. C. (1949). The effect of prior residence upon dominance in the fish Platypoecilus maculatus. Physiological Zoology, 22, 161-169.

BronsteIn, P. M. (1985). Predictors of dominance in male Betta splendens. Journal of Comparative Psychology, 99, 47-55.

Evans, C. S. (1985). Display vigour and subsequent fight performance in the Siamese fighting fish, Betta splendens. Behavioural Processes, 11, 113-121.

Figler, M. H., Dyer, R. S., Streckfus, C. F., \& NARdini, K. M. (1975). The establishment of dominance relations in the jewel fish, Hemichromis bimaculatus (Gill), as related to prior exposure to and configuration of visual cues. Behavioral Biology, 14, 241-245.

Figler, M. H., \& EINHORN, D. M. (1983). The territorial prior residence effect in convict cichlids (Cichlasoma nigrofasciatum Günther): Temporal aspects of establishment and retention, and proximate mechanisms. Behaviour, 85, 157-183.

FigLER, M. H., \& EvENSEN, J. (1979). Experimentally produced prior residence effect in male convict cichlids: The role of initial proximity to territorial markers. Bulletin of the Psychonomic Society, 13, 130-132.

Figler, M. H., Klein, R. M., \& Peeke, H. V. S. (1976). The establishment and reversibility of dominance relationships in jewel fish, Hemichromis bimaculatus Gill (Pisces, Cichlidae): Effects of prior exposure and prior residence situations. Behaviour, 58, 254-271.

Figler, M. H., \& PeeKe, H. V. S. (1978). Alcohol and the prior residence effect in male convict cichlids (Cichlasoma nigrofasciatum). Aggressive Behavior, 4, 125-132.

Figler, M. H., WaZlaveK, B. E., Spencer, F. P., \& Gussio, R. P. (1985). The influences of chemical cues on the territorial prior residence effect in convict cichlids (Cichlasoma nigrofasciatum Günther). Aggressive Behavior, 11, 207-216.

Figler, M. H., Wazlavek, B. E., Walko, B. A., \& Chaves, L. M. (1985, November). Intruder size advantage and territorial behavior in convict cichlids. Paper presented at the meeting of the Psychonomic Society, Boston, MA.

Maynard Smith, J., \& Parker, G. A. (1976). The logic of asymmetric contests. Animal Behaviour, 24, 159-175.

(Manuscript received for publication May 22, 1986.) 